\title{
Controlling the UnControllable: Agile TeAms And Illusions of Autonomy in CREATIVE WORK
}

\author{
Damian Hodgson \\ Manchester Business School, University of Manchester, UK \\ Louise Briand \\ Université du Québec en Outaouais, Canada
}

\begin{abstract}
The creative industries have recently been hailed as presenting a liberating model for the future of work, and a valuable terrain on which to examine purported new regimes of workplace control. This article, based on the empirical examination of a Canadian video game development studio, traces the modes of control which operate on and through project teams in creative settings. The impact of the adoption of an 'emancipatory', postbureaucratic project management technology, 'Agile', is critically examined through interviews and non-participative observation of management, technical and artistic labour within one project team. The potential for autonomy in such 'Agile' teams is critically assessed within the managerial regime of creative production and the broader power relations implied by the financial, organisational and institutional context.
\end{abstract}

\section{Keywords}

teamwork / autonomy / creativity / project management / creative industries

Acknowledgements: We would like to acknowledge the support of the Social Sciences and Humanities Research Council of Canada (SSHRC) who provided funding for this research 


\section{Introduction}

In recent years, unprecedented attention has been paid to creative industries in developed countries, which are often portrayed as a path to national competitive advantage in the face of global competition in manufacturing and increasingly in service industries (Florida, 2002; DCMS, 2008). In the midst of this celebration of creative labour in the 'New Economy', many writers have also looked to creative industries for insights into how to square the circle of creativity and control in other, traditional industries (Townley and Beech, 2010). Creative industries, it is argued, epitomise the virtue of empowering, flexible and knowledge based production systems - akin to Peters' 'liberated firm' (1992). In doing so, they stand as an implicit rebuke to the failure of the traditional machine bureaucracy and inflexible Fordist production processes and value chains (Hesmondhalgh and Baker, 2011). Others, questioning emancipatory claims for the sector, argue that stereotypes of liberated work in the creative industries must be empirically and critically examined (Banks, 2007; Smith and McKinlay, 2009).

A key issue overlooked in much of this literature is that the creative industries are dominated by work and management by project, an organisational and managerial development which has also been uncritically lauded in many quarters. The majority of work within creative industries is fundamentally project-based, a fact which imposes a particular logic of action on the field, in terms of finance, temporality, autonomy and accountability (Hodgson and Cicmil, 2006). For its proponents, project-based work offers emancipatory possibilities, moving beyond hierarchical control towards empowering and fulfilling work which can liberate and reap the benefits of worker initiative and creativity (Peters, 1992: Roy and Audet, 2003). For others (Clegg and Courpasson, 2004; Hodgson, 2004), the project- 
based organizational form indicates, rather, that control in projects has been strengthened by project management systems and technologies. To understand work in creative industries, it is therefore vital to examine empirically the nature of project-based organising, and moreover, recognise the diversity in project management, from traditional, neobureaucratic project management methodologies invented in large-scale construction and engineering projects to newer, 'post-bureaucratic' methods which claim to offer more flexible, empowering alternatives.

The intention of this article is therefore to subject project work in a particular creative industry, video game development, to critical scrutiny by exploring the operation of an 'emancipatory', post-bureaucratic project management technology, 'Agile/Scrum'. First of all, changing approaches to project management and teamwork are located in the broader context of research into creative industries. Given the challenges of managing creative technical and aesthetic work in such sectors, attention has turned to 'emancipatory' forms of project management to control the 'uncontrollable' aspects of such work. The paper examines the operation of a specific game development project, examining the way in which work is structured, allocated, monitored and controlled following the adoption of Agile project management philosophy and Scrum methodology. Although Agile and Scrum emphasise collegiality, mutual adjustment and rational democracy, the study indicates how this is undermined by regular interventions from senior management, and also by the persistence of an emphatically hierarchical division of decision-making power within the team, and micro-political actions to influence decision making and engineer decisions on the part of senior management within the team. A more persistent challenge to the management systems was presented by the resistance of the artists and animators to Agile monitoring systems, resulting in a forced return to personal control for some aspects of 
creative work. The article thus both illustrates the basis of the effectiveness of such project management technologies, but also their limitations in effectively controlling the full round of creative production.

\section{Locating game development in the creative industries}

The last fifteen years has seen an increased focus on both creative industries and creative processes within traditional industry, often linked to claims of moves to a 'weightless economy' (Coyle, 1998). This has been accompanied by work which extols the economic importance of creative work to current and future competitiveness of developed countries faced with the loss or relocation of the manufacturing base and increasingly of service industries to developing countries (Florida, 2002; Bilton, 2007). The wider impact of this discourse has been the use of creative industries to represent and legitimise an alternative to the 'old economy', representing instead "a new economic and organizational model characterized by self-employment, autonomy and flexibility, a highly skilled workforce of highly motivated freelance individuals, clustered into communities and networks of specialist knowledge and expertise" (Bilton, 2007: 173).

The most widely-cited definition of the creative industries, deriving from the early work of the UK Department for Culture, Media and Sport, describes them as sectors "which have their origin in individual creativity, skill and talent and which have a potential for wealth and job creation through the generation and exploitation of intellectual property" (DCMS, 2001: 5). The video game industry represents the largest sector within the broadly defined 'creative industries' (NESTA, 2010), and was recently argued to be worth $£ 30.9$ billion worldwide (PricewaterhouseCoopers, 2008). In terms of structure, production process, market and consumption pattern, the industry reflects other collective creative industries 
such as film and popular music. Specifically, the video game industry is a particularly risky business, marked by a dialectic of control and creativity, with high production costs and low reproduction costs, producing semi-public goods (Hesmondhalgh, 2010; Dymek, 2010). Consequently, as with other creative industries, publishers in this industry rely on repertoires to offset misses against hits, demand is created by engineering artificial scarcity, the market for video and computer games is formatted by the creation of genres, serials (franchises) and to some extent, 'stars', and to a lesser extent, tight control of distribution/marketing is offset by looser control of 'symbol creators' (Hesmondhalgh, 2010). Nonetheless, the video games sector is routinely ignored in comparative studies of creative industries and it remains under-researched in comparison to film and TV, for instance.

One explanation for this neglect is in part due to perceptions of video game development as primarily a technical industry, a subsector of software development and ICT, which tends to obscure or dismiss the creative, artistic and indeed ludic dimensions of work in this sector. In the broadest sense, employees in this industry might be described as "knowledge workers', insofar as they are part of the so-called 'new economy', their work is often varied and dynamic rather than routine, they rely upon specialist expertise and they expect and require considerable autonomy in their roles (Benson and Brown, 2007). Indeed, the closest parallel for video game development might be expected to be software developers, who are seen by many as archetypical knowledge workers (Marks and Scholarios, 2007); a parallel further supported given the stratified nature of work in creative industries as in software development (Marks and Baldry, 2009). 
In many senses, however, this definition obscures as much as it reveals. As Warhurst argues (2010: 226), "there are clear overlaps in the claims made about the knowledge and creative economies". However, conflating knowledge and creative work neglects the aesthetic, cultural and experiential product of the latter. "Knowledge-intensive commodities are not symbolic goods dominated by aesthetic attributes" (Thompson et al, 2009:67), and in the production of symbolic goods, technical creativity must be combined with aesthetic creativity. Game development is distinct from normal software development as it involves "a complex mix of technology, art, and interactive story-telling" (Cohendet and Simon, 2007: 587), combining the work of script-writers, actors, graphic artists, sound engineers, animators as well as software programmers. The managerial challenge of this industry, unlike many other field of knowledge work, lies in the integration of artistic and technical creativity, and negotiating the complex relationship between management, art and technology.

\section{Managing creativity through projects}

Across the creative sectors, the "indeterminacy/unknowability of creative production" (Caves, 2002) poses particular and possibly unique challenges for the management of this production process (Lampel et al, 2000; Lawrence and Phillips, 2002; Tschang, 2007). There is a widely-accepted premise in much of this work that "creative workers' search for autonomy and the intangible nature of intellectual assets requires and results in an abandonment of the traditional, hierarchical structures and practices of industrial society" (Thompson, Jones and Warhurst, 2009: 53). Analysing the management of creativity is further complicated by the romanticisation of the creative individual, and the construction of an opposition between creative logics with the logics of commercialisation and 
management, the battle between 'creatives' and 'suits' (Scase, 2002, in Thompson et al, 2009: 51).

Moving beyond this sterile opposition involves dismantling the Romantic stereotype which sets up individual creativity against its antithesis, management. Firstly, a number of authors challenge the individualistic basis of creativity, emphasizing instead both the collaborative, collective and even systemic nature of creative work (Bilton, 2007). A second argument against this stereotype draws attention to the difficulty of differentiating creative and 'noncreative' labour, emphasising the routine aspects of creative work and the creative aspects of routine work. It is argued, therefore, that "all labour contains a creative element" and, conversely, "most labour, even that of an artist, has a routine or familiar component" (Smith and McKinlay, 2009: 32). These various arguments suggest a much closer, less contradictory relationship between control and creativity than is often assumed, but also point towards a distinctive mode of management typically enacted in the control of creative work. Townley and Beech (2010: 7) describe this as tracing "the inherent tension between the freedom to be creative and keeping this creativity within manageable and productive bounds... maintaining the tension and balance between creativity and cost, autonomy and management control". The challenge for management in creative sectors is therefore depicted as the need to "(build) creative systems to support and market cultural products but not allowing the system to suppress individual inspiration, which is the root of creating value" (Lampel et al, 2000: 263).

In terms of the control of labour in creative industries, much attention has been paid to the use of contracts as a mode of control (Caves, 2002), and relatively less on intra-firm control systems. Caves thus argues that the unpredictable demand for creative products is dealt 
with by the use of open-ended contracts, Thompson et al (2009) similarly suggest that creativity in such industries is managed by contract, product portfolio or distribution sphere rather than the labour process, and that "unlike classic industrial or service work, or even traditional creative workers such as scientists or other expert labour, the tensions in the management of creativity are located largely outside the employment relationship" (Thompson et al, 2009: 57). While contracting clearly forms part of the dynamic of control, this ignores the detailed technologies of project management in operation in many creative industries dominated by "project based organisations deploying flexible technologies used by labour in high-trust but ephemeral teams" (Smith and McKinlay, 2009: 29). For its proponents, the project-based organizational form involves giving up traditional bureaucratic and hierarchical structures, and conveys a desire to break with the tendency to control, so as to liberate worker initiative (Peters, 1992; Roy and Audet, 2003). For other authors (Clegg and Courpasson, 2004; Hodgson, 2004), the project-based organizational form is the primary mechanism of workplace control in many industries, built upon "modernist emphasis on comprehensive planning, linked to a reassertion of the importance of strict managerial control and professional self-discipline" (Hodgson, 2002: 810). The strong rationalist principles underpinning traditional project management, following the clear 'plan-monitor-deliver' format, bounded by the 'iron triangle' of cost/time/quality and reliant on the fragmentation and quantification of labour would, on the surface, appear to have little to offer creative industries, where success is predicated on inspiration, excitement, passion and romantic genius. Nonetheless, where projects exist, project management tends to follow, accompanied by "codified formulas and routines of planning, budgeting, and managing projects as distinct organisational units" (Grabher, 2002: 1911), 
often in jarring conflict with the nature of work and the expectations and self-perceptions of workers in creative industries.

The limitations of traditional project management are not unknown in the field - indeed, it might be said that project management is in the process of reinventing itself, reconsidering certain anachronistic assumptions which often result in approaches which fail to deliver even in its traditional domains of engineering and construction (Winter et al., 2006). The result has been a search for more flexible and emancipatory ways to organise project work and the proliferation of alternative project management methodologies and team structures (Harley, 2001; Beirne, 2008). These developments echo many of the debates on teamworking in recent years. While teamworking has been a persistent theme in the restructuring of work across a range of industries for over half a century, several writers have identified distinct waves of adoption (Mueller et al, 2000; Van den Broek et al, 2004). The revival of teamworking since the 1980 s draws its impetus from interest in TQM and Toyotaist production techniques, popularised as 'lean production', and often combined with moves towards 'high performance work systems (Appelbaum et al, 2000).Many writers differentiate this recent wave of interest in teamwork from earlier movements in the 1960s and 1970 s due to its instrumental philosophy, largely replacing earlier concerns with the 'humanization of work', job enrichment and workplace democracy (van den Broek et al, 2004; Bacon and Blyton, 2005) with their roots in Socio-Technical Systems, the Tavistock School and the Quality of Working Life movement. It is therefore no surprise that there persists a strong critical tradition which challenges the rhetoric of empowerment implicit in new teamworking (Knights and McCabe, 2000; Harley et al, 2001), identifying the operation of 'concertive control' (Barker, 2003) and peer or self-monitoring (Sewell, 1998) to further strengthen managerial control in such settings. Nonetheless, several authors emphasise the 
need to play close attention to the variety which exists within teamwork (Procter and Currie 2004; Bacon and Blyton, 2005) and to critically evaluate the degree of meaningful autonomy in each context to capture the different meanings and effects of teamwork.

In many senses, the emergence of 'Agile' and similar new project management methodologies represent the most serious attempt to integrate the principles of modern teamworking with project management. Agile was most clearly articulated in a set of principles known as the Agile Manifesto, emerging from a meeting in February 2001 of 17 software developers in reaction to the perceived micromanagement of project management technologies in the field. The widely circulated Manifesto states;

We are uncovering better ways of developing software by doing it and helping others do it. Through this work we have come to value:

Individuals and interactions over processes and tools

Working software over comprehensive documentation

Customer collaboration over contract negotiation

Responding to change over following a plan

That is, while there is value in the items on the right, we value the items on the left more.

The supporting Twelve Principles (Agile Alliance, 2012) reproduce the language of modern teamworking literature, referring to projects "built around motivated individuals", reliance on trust, internal communication and internal reflection, dialogue and adjustment. Various methodologies emerged following this to offer practical guides operationalising the principles of Agile. One of the most influential methodologies, labelled Scrum (Schwaber 
and Beedle, 2002), combines regular internal communication with intensive iterative cycles to solve production problems adaptively within an 'empowered' team structure. It is argued by proponents that Agile and methodologies linked to Agile (eXtreme Programming, Scrum, etc.) deliver better results through the flexibility and commitment which can be delivered by "tight, self-organizing teams" (Agile Alliance, 2012)

In the empirical research below, then, the following questions are explored. First, how far do new forms of project management such as Agile/Scrum depart from traditional rationalist approaches to the control of project work? Secondly, and in light of critical debates on teamworking, to what extent do such approaches enable meaningful autonomy to be delivered in project teams? Finally, to what extent do such approaches offer a substantive alternative for the management of collective creative labour in creative industries and more widely?

\section{Methodology}

The empirical focus on this research is a team working in a medium-size Canadian studio (approximately 200 developers) in the video game industry, given the pseudonym 'StudioOne'. The studio is a wholly-owned subsidiary of a global video game publisher and developer, here referred to as 'Videocorp', which employs more than 3000 developers worldwide. The case study presented below forms part of a 3-year research program involving three video game development firms. This research program aims to examine the control and autonomy of knowledge/creative workers in project-based organisations in creative industries. The focus here is on one project team, 'Gameteam', within StudioOne.

Data collection was based primarily on semi-structured interviews and non-participant observation techniques. Data collection aimed to document the 'three crucial dimensions of 
management' (Audet and Déry, 1986), that is, planning, coordinating and surveillance. Over a six-month period, 13 interviews were conducted on-site with 12 individuals (directors, producer, game designer, team leaders and developers, the latter category covering programmers, artists and animators). Interviews lasted between 60 to 90 minutes and were tape-recorded and fully transcribed. Eleven full days of non-participant observation were also carried out with the specific purpose to capture the dynamics of the relations between team members over the duration of the project. Non-participant observation involved sitting close by and listening to presentations and conversations between team members at meetings ("scrums," "sprint reviews," "planning sessions," "poker planning sessions," "brainstorm sessions," "project management committee meetings") and various casual encounters.

The fieldwork was conducted by one of the paper authors and a research assistant. To ensure reliability and validity, interviews were tape-recorded and fully transcribed before being shared with the first author who did not participate directly in fieldwork; transcriptions and observation notes were discussed by the entire research team regularly throughout the project. The data collected from the various sources was analysed with the aim of describing and developing general conclusions on the way creative projects are managed. In an inductive approach, the data collected was analysed in an open-ended and exploratory manner to allow detection of patterns on planning, coordinating and monitoring (Silverman, 2006). Key themes emerging from detected patterns were discussed with the author not directly engaged in the empirical research, who would challenge inferences, request corroboration/evidence or propose alternative explanations in light of the 'enfolding literature' (Eisenhardt, 1989). Through this critical dialogue, a detailed and 
plausible account emerged of the organisation of Gameteam and its internal and external dynamics over the course of the project.

\section{Gameteam and its environment}

This section presents the general environment of Gameteam. It includes details of the following: the organisation of StudioOne, the project developed by Gameteam, the standard structure of a project, a succinct statement of current policies across Videocorp, and the team composition and responsibilities assumed by the members.

Founded by Videocorp in 2005, StudioOne was a substantial game development studio with a staff of approximately 200 permanent developers (programmers, animators, artists, etc.), supplemented by temporary workers, typically students from training programs. The StudioOne general manager was assisted by a management team made up of producers and managers from three departments: Communications, Operations, and Human Resources. The unit of analysis, Gameteam, was charged with developing a new edition of an existing game for the Nintendo $\mathrm{DS}^{\circledR}$ console. The project was assigned a time frame of approximately nine months, with a deadline set for September for the game to be published by Christmas. As the project moved ahead, Gameteam was assigned human resources in accordance with requests put forward by the producer.

It should be noted that projects at Videocorp are structured around a sequence of four predefined stages: ideation/conception, pre-production, production, and quality control. Each stage refers to a set of specific activities (general description of the game, technology development, sound integration, etc.) and definite outputs (prototype, sequences of the game, full game, tested version of the game). The stages of the project are typically

subdivided into several sub-stages separated by 'decision gates' based on Stage-Gate ${ }^{\circledR}$ 
project management methodology. At each 'decision gate', Videocorp approval must be given before the team can progress to the next stage.

The sequence of stages implies variations in the team composition: the ideation/conception stage involves the 'core team members' only e.g. producer, artistic director, game designer and team leaders, one for each trade (program, artistic, animation). At the pre-production stage, a few developers from each trade join the core team, while production stage requires a full team (from 30 to 150 individuals). Finally, at the quality control stage, the team become smaller, now including only the core team members and a few developers (primarily programmers) to carry out small adjustments. When our study began, Gameteam was already fully formed. The team consisted of approximately 20 individuals: a producer, a game designer, three team leaders, and a few developers from each trade, whose number varied with each stage. By September 2009, the team was down to a few developers, mostly programmers, who were busy correcting problems pointed out by the testers. At any given time, the team consisted of developers whose average age was approximately 25 years. It is also worth stressing that the team was mainly composed of men, but that all interviewees are reported as 'he' in order to protect their anonymity.

Moreover, at Videocorp, the activities of project teams are substantially framed and determined by the policies and decisions of the firm and the actions of the cross-functional departments at StudioOne. Videocorp sets the policies and establishes very clear guidelines concerning the delegation of authority; the main administrative systems (related to finance and human resources) are centralised; reports on the progress of projects, pay scales, and even the expense accounts of StudioOne's general manager, are examined and approved by Videocorp; the studios' profitability is followed very closely by Videocorp through a 
centralised budget control system; and lastly, quality control is, by requirement, ensured by Videocorp.

The composition of Gameteam follows a set of rules that are regulated by the Operations and Human Resources departments. Operations are responsible for ensuring the optimal use of resources and do so by assigning workers to teams in accordance with a formula based on "worker-months," depending on the type of game and console in question. Only senior management at Videocorp head office are "in" on this "secret" formula. Producers can ask for a particular resource for their team but there is no guarantee that requests would be granted as the resource may have already been assigned to a different project by the Operations department. The requests made by producers are subject to corporate benchmarks, reflecting defined levels of competence for each trade corresponding to a level of responsibility, and the overall need to optimise resources.

The main roles in the team were the producer, the designer, the artistic director, plus three team leaders reflecting the three main specialisms (programmers, animators and artists), each in charge of a number of developers in each specialist field. The producer, while not involved in the actual production tasks, saw himself as ultimately responsible for the production of the game, a role akin to a project manager. In his own words, it was his head that was "on the block." The game designer decided on and wrote out the scenario of the game. It was his conception of the game that determined all the ensuing tasks - or stories which were stored in a central file called the backlog. The artistic director was responsible for deciding on and illustrating the appearance and atmosphere of each part of the game (e.g. conveying the feeling of heat). He worked closely with the team leader of the artists' group. For their part, team leaders were responsible for coordinating the activities of the 
three different groups of specialists and they participated, along with the producer and game designer, in maintaining the backlog (examining tasks, setting priorities, etc.). Finally, the developers were specialists belonging to one of three main groups, that is, programmers, animators and artists, straddling the technical and aesthetic aspects of game development. The developers' role was to create the game, including its characters and textures, etc., based on the scenario worked out by the game designer.

\section{Managing creativity through Agile project management}

This section presents details pertaining to the decision to adopt Agile project management and to implement this using Scrum methodology, describing the working of technical aspects of Agile and Scrum ('sprint, 'sprint review', 'scrum', 'burn down chart', etc.) and an overview of the distribution of power within the Gameteam.

With the consent of StudioOne, Gameteam's core team decided from the outset to adopt an alternative project management approach to enhance collaboration and support creativity. The chosen approach, 'Agile', reflected the preference of developers for a flat, collegial structure, particularly in the relationship between team leaders and the developers. Thus, the producer held the view that there was no hierarchical authority in the Agile team, arguing that he operated in "convince mode", seeking "commitment" from the team. Although the game designer played a central role with regard to the scenario of the game, this was described as merely a general blueprint that did not dictate every task or the way tasks would be carried out. In fact, the members of the core team expressed the hope that the developers would take responsibility for the project:

Basically, the main thing is this: we [the core team] don't want the core team to carry the project... Our goal is really to have a team that is committed to its 
project; it's their project. We want them to take matters into their own hands, that's the key... If we're always telling them how to do things, they won't find their own solutions, they won't necessarily get to the point where they can work out the problem for themselves. So, that's our goal, really, to give the people on the floor power over their own decisions. (Producer)

Similarly, the three team leaders expressed a loathing for hierarchy and saw themselves not so much as leaders but as guides or, in their own words, "coaches".

The 'Agile Manifesto' was posted prominently on a wall next to Gameteam's work station, and the team espoused Scrum methodology. In accordance with Scrum, Gameteam's project timetable was divided into 3-week phases called "sprints." Each sprint started with a planning session and ended with a review, followed by a post-mortem: these sessions involved all the team members and had the aim of enhancing communication between trades and supporting individual accountability. Artists and animators tended to remain silent at these meetings, which were dominated by the more technical developers.

After planning sessions, the members of the team met in sub-groups to discuss the tasks, to agree their level of complexity and duration, and to assign them among team members. This information formed the 'backlog', a work breakdown schedule which served as a key monitoring tool, ensuring that everyone shared a common understanding of the goals and keeping track of all the task assignments. An example of what this meant in practice can be seen in the activity of job estimation for the programmers. Assessing the man-hours allocated to each task was done collectively, through a standard Agile process called "poker planning". In poker planning, each team-member estimates the amount of work required for each task. Estimates are then simultaneously revealed - if the estimates differ, team- 
members each explain their estimate, after which each person estimates again. This cycle continues until consensus is formed. In principle, then, 'poker planning' enables open and frank communication and exploration of all viewpoints and thus exemplifies the Agile philosophy adopted by Gameteam.

During the three-week sprints, Scrum required short daily meetings ('daily scrums') for each trade group. This meant that at a specific time each day, the programmers, artists and animators held simultaneous, separate, 'scrums'. Meetings were held standing in a circle near the team work station and each was led by the 'ScrumMaster', i.e. a developer chosen among and by each trade group. The ScrumMasters invariably started the meeting by asking each developer to give a brief account of how his work was progressing, difficulties he had encountered and solutions he was considering. Such "daily scrums" lasted no more than 10 minutes and were followed by the "scrum of scrums" involving only the ScrumMasters to support coordination between groups. The producer, game designer, and team leaders did not participate in the daily scrums. However, any pertinent information or requests that came up during the scrums were conveyed to them.

ScrumMasters are therefore developers without positional power; team members emphasised that they were not 'anyone's boss' and that they acted merely as 'facilitators', 'to help get the job done'. ScrumMasters' primary concern was the project and they often had to prevent last-minute requests from above from derailing the scheduled progress of the team; an interesting challenge for a developer without positional power:

What we're looking for [in a ScrumMaster] is soft skills, because his job is to remove anything that might get in the team's way and prevent it from delivering the sprint. So, when I go on the floor and ask the team to tweak something, I 
know the ScrumMaster might say: "You know that if you ask for that, you're going to have to drop such and such a thing?" And I'll say, "Oh no, I don't want to drop that. Okay, I won't ask then. Thanks." (Producer)

In accordance with the Scrum methodology, the team kept track of its progress using the 'burn-down chart' displayed on a wide screen next to the workstation. The chart was updated on a real time basis through the backlog and it displayed the team's progress. The system could also provide charts for each team members and trades.

A perceived strength of Agile/Scrum was therefore the ability to incorporate suggestions from across the team, retaining flexibility as far as possible and placing responsibility on the shoulders of developers and not just management. The consequence of these arrangements was the perception that the team operated democratically and with a significant degree of autonomy. All of the team members interviewed expressed the view that the developers were not confined to simply carrying out orders but could draw on an intimate knowledge of their specialism to develop innovative ideas. Thus any of the developers could suggest changes to the scenario, although the game designer was finally responsible for the game scenario. Similarly, the developers argued that they controlled their own time within the limits imposed by the needs of their peers, subject also to the various interdependencies in work tasks, and, vitally, as long as they respected the goals of the sprint, which they felt they had helped to define. This complicity in the definition of goals, targets and deadlines served as a powerful mechanism to shift responsibility onto developers, in the belief that these are self-imposed through an open and power-free process.

\section{Analysis and discussion}


In this section the previously discussed challenges and contradictions that face the creative industries are explored through a detailed case study. The analysis is structured around three sections. In the first, the persistent framework of power relations within Gameteam is described, providing a context for an examination of the limited autonomy allowed to Gameteam in light of the dominant regulation of team behaviour by the studio and the wider corporation. Finally, particular attention is paid to the way in which artists and animators within the team evaded or refused to participate in the project management technologies implemented in Gameteam, and the alternative forms of control used to influence the aesthetic labour component of the team.

Despite regular affirmations of the flat, democratic and egalitarian culture in operation in the team, various observed encounters undermined such claims. Despite the use of Agile/Scrum methodology, the persistence of power relations was evident in the actual operation of various elements of Scrum, for example during the 'poker planning' sessions where the duration of tasks were collectively determined. It was observed that while the procedure was applied in full, the discussion was actually rather limited with the team leader's point of view tending to prevail over that of the other programmers, and junior members of the team learning swiftly to adjust their estimates in later rounds to match that of the senior members. Steering this process and (diplomatically) directing the discussion is therefore a key exercise in soft power, particularly to do so without undermining the appearance of rational democracy in action essential to 'tie' individuals to the collective decisions of the session. It was no surprise, then, that the final decisions largely reflected informal power hierarchies. 
Although such hierarchies were largely implicit, the senior management within Gameteam felt it necessary at a certain point to clarify the 'shadow' power structure of the team, so as to encourage the developers to take greater responsibility for the project. So, during a sprint review attended by all the members of the team, the producer took the opportunity to clarify and emphasise the distribution of decision-making power within Gameteam. The organisation chart was divided into three hierarchical levels, each represented by a specific colour and accompanied by the following legend:

1. Producer and game designer (pink): "decision-making power"

2. Team leaders (yellow): "decision-managing power"

3. Experts (purple): (no reference made to power).

The perceived need to articulate an explicit hierarchy with levels of power reflects higherlevel concern with the flat, collaborative structure initially envisaged, and perhaps the specific kind of participation. However, in line with the observation of the 'poker planning' session, it would be more accurate to report that the power differentials and hierarchy did not disappear as a result of the adoption of Agile and Scrum; instead they coloured the application of Scrum methodology to control the team behaviour.

Autonomy for Gameteam was further circumscribed by the active presence of Videocorp and of StudioOne at each stage. While the producer was nominally free to structure his team as he saw fit, he was required to do so within the confines of the hierarchy of responsibility established by Videocorp. Critically, Videocorp set the major deadlines and decided whether or not each stage had been successfully completed. In practice, this largely undermined the autonomy afforded by Agile project management, since Videocorp often disrupted the goals that had been set: as one manager explained, “Head office doesn't work 
in sprints and when it asks for something, it's always for tomorrow". Particularly at the start of the project, the 'game stories' were often turned upside down by needs that "came from everywhere," and in particular, from Videocorp.

It was possible for a team to attempt to stay "off Videocorp's radar" due to the geographical distance that separated them; however, despite their efforts, the Gameteam producer still found it necessary to ask the general manager of StudioOne to intervene with regard to the number of requests being made by head office. Although work tasks and methods were controlled by Gameteam, many more significant decisions - over quality standards and targets, the appointment of producer, designer, and formal team leaders - were made by StudioOne or Videocorp itself, or else determined by regulations. The team, it seemed, were at best semi-autonomous (Gallie et al, 2011), free to make decisions, but in conditions not of their own choosing.

However, a more substantive challenge to the operation of Agile/Scrum was presented by the failure of members of the team to comply with even this new 'liberated' regime. While the key components of Agile/Scrum methodology - scrums, sprints, poker planning sessions and so on - were embraced by the programmers, these approaches were resisted by members of the other two specialist groups, the artists and the animators. As reported by a team manager;

We have a problem because the artists aren't Agile. They detest it!... It's hard to get the artists on board with Agile. One of the Agile Scrum Masters is an artist, but he isn't Agile. That's a problem. There's a dual system happening here. (Producer). 
As a result, the surveillance of their activities was necessarily partial and unreliable in certain respects and the backlog and burn-down chart were inaccurate. Whatever approach was used to assess and divide up the tasks, the backlog was the favoured tool for keeping track of the work to be carried out and the projections concerning it. However, the artistdevelopers, not being "Agile," sometimes failed to update the backlog. Various meetings central to Agile/Scrum - the daily scrums, the three-weekly sprint reviews, and so on - relied upon accurate information and hence regular updating of the backlog. The ability of the system to see the current state of progress of each task at any given time was thus undermined by the actions of the artists who had decided not to enter accurate data into the database.

With indivisible and immeasurable tasks to perform, and inspired by a belief in individual ownership of work instead of the interactions and dynamic calculations of the programmers, artists and animators appeared to exist outside of the Agile project management.

The challenge for artists is that things can be very hard to identify. In programming, everything is very Cartesian. Their tasks are very mathematical and can be quantified. But in art, for one, it's hard to quantify the work, and for two, there are days when you're inspired and days when you're not, and it's hard to manage that. (Team leader).

As a result, alternative approaches were used to monitor and assess the work of the animators and artists. For senior management within Gameteam, the pragmatic response was to turn to personal monitoring to capture in an informal manner information on the artists' and animators' progress: 
We [the senior managers and team leaders] have learned to ask them how things are going: "So, what are you working on? Have you had any problems with it?" We got that from Agile. But tracking tasks, poker planning, and all that, we don't use any of that for the artists. We reserve that for the programmers. But try telling the artists: "We need your decors ready for such and such a date"? Good luck! (Producer)

Although the animators and artists had to be 'excluded' from Agile's task tracking and time monitoring systems, poker planning and similar technologies because of the nature of their work, this does not imply that they experienced significant autonomy. The artists' work, although imaginative and original, was oriented by the vision defined by the art director and the 'concept art' he prepared. Similarly for animators, the need to create a consistent set of animations implies a certain homogeneity and requires that the team leader has a direct and personal influence on the work of each group. Thus the animation team leader states;

My role is to standardize. One animator will tend to be more extravagant, one will animate more 'bang bang' and it does not work... [when playing a game, one must not see] that there are four different animators who made the animations. (Team leader).

Reliance upon such personalised and time-intensive forms of control recalls long-established practices in craft labour (Sennett, 2009) and a distinct logic of control to that of Agile/Scrum. Interestingly, it was also observed that spaces where autonomy was afforded to staff were not necessarily sought or valued by developers. Between projects, the developers were typically allocated some "off-project" time. In the eyes of the producer and team leaders, this time represented the freedom to explore new avenues and do "crazy things" - in other 
words, to be creative. However, it appeared that developers put very little effort into these activities, which they saw as a waste of time or, worse, a sign that their talent was not appreciated. This phenomenon challenges the assumption that creative workers seek and value autonomy. Instead, it seems, several appear to perceive non-directed work time as a challenge to their sense of worth, rather than an opportunity to escape managerial control.

To sum up, the adoption of the Agile/Scrum methodology by Gameteam had limited success in initiating real autonomy within Gameteam or any of its individual members. The limited autonomy implicit in Agile project management resulted in a degree of conflict with the parent organisation whose structures, decisions and impromptu demands overrode local agreements. Moreover, observation of the processes in action indicated that despite the rhetoric, power hierarchies persisted in practice within the team, evident in the process of enacting the methods of Agile/Scrum, and eventually requiring a rearticulation of the power structure. Finally, the control imperative within the arrangement became explicit where it faced its limit in the refusal of the artists and animators to participate in Agile project management practices, thus undermining the viability of the system.

\section{Conclusion}

The key aim of this article has been to consider the novelty and effectiveness of new forms of control which operate on and through project teams in creative industries. The study above provides evidence that the nature of work in game development indeed obstructs many traditional modes of control, leading to attempts to introduce novel control technologies such as, here, Agile project management, enacted using Scrum methodology. While Agile/Scrum here resulted in a system where the members of Gameteam, collectively, had influence over the choice of tasks, work methods, and to a degree, quality standards, 
more substantial decisions related to work effort, targets, resource allocation and the selection of team members were imposed on them externally. The team's developers and leaders enjoyed autonomy, but only within a context wherein governing and surveillance mechanisms were defined and activated by actors or authorities outside the team. The article also explores the distinctive intra-firm management control systems impinging upon the day-to-day aspects of project-based working and management. Despite repeated assertions that Agile and Scrum enabled the devolution of power to the team, the empirical research highlights the persistence of power hierarchies within and around the project team. In this context, the team fell some way short of 'self-managing' (Nijholt and Benders, 2010).The study indicates that these attempts to reinvent control in projects do little to alter established power structures around projects, and even within projects themselves. As Banks (2007: 72) argues, "through introducing such 'emancipatory' mechanisms as the 'project team', managers are increasingly adopting the seductive veil of 'facilitator' or 'friend of creativity' in order to mask the pervasive reapplication of traditional and formulaic management in the interests of capital accumulation".

There, are, however, limitations to the reach of these new project management technologies, particularly given the need for a control system to capture both technical and aesthetic work in this sector. Within Gameteam, the artists and animators in rejecting Agile/Scrum manage to evade control technologies to a degree. Here, team management are forced to fall back on modes of personalised control, long established in craft industries. This lends some support to those, such as Smith and McKinlay, who are sceptical regarding the effectiveness of project management in this context, suggesting that "it remains to be seen the extent to which industry standard modes of project management bureaucratise such tacit knowledge, and whether such administrative innovations target the technical and 
economic aspects of creative labour and remain frustrated by the elusiveness of 'creative' labour" (2009: 25).

Although a limited study in terms of scope, this detailed exploration has illustrated both the effectiveness and the limitations of an explicitly post-bureaucratic and emancipatory system of project management. Agile project management is widely represented as an approach which supports emancipation of knowledge workers, freeing them to use their own initiative and creativity and offering an alternative to standardisation and bureaucratic processes for the management of knowledge-intensive firms and, in particular, creative organisations. Even 'enlightened' 'Agile' project teams and management represent, it is argued, a set of management tools which are based on "softer" monitoring mechanisms, certainly, but which nonetheless sustain control in a hybrid form. To the extent to which claims of emancipation and autonomy are accepted by team-members, they offer the possibility of a powerful ideological form of control. However, aesthetic and symbolic labour appears relatively resistant to such activities, pointing towards the limits of possibility of such new project management practices. Given the current vogue for the adoption of Agile and similar methodologies, there is a pressing need for more extensive, cross-sectoral, and critical research into its implementation and the consequences for control.

\section{References}

Agile Alliance (2012) The Agile Manifesto Available at: www.agilealliance.org

Audet, M et Déry, R (1996) La Science Réfléchie : Quelques empreintes de l'épistémologie des sciences de l'administration. Anthropologie et sociétés, 20(1): 103-123.

Banks, M (2007) The Politics of Cultural Work. Basingstoke: Palgrave. 
Beirne, M (2008) Idealism and the Applied Relevance of Research on Employee Participation. Work, Employment and Society, 22(4), 675-693.

Benson, J and Brown, M (2007) Knowledge Workers: What keeps them committed; what turns them away. Work, Employment and Society, 21(1): 121-141.

Bilton, C (2007) Management and Creativity: From Creative Industries to Creative Management. Oxford: Blackwell.

Caves, RE (2002) Creative Industries: Contracts between Art and Commerce. London: Harvard University Press.

Clegg, S and Courpasson, D (2004) Political Hybrids: Tocquevillean views on project organizations. Journal of Management Studies 41(4): 525-547.

Cohendet, P and Simon, L (2007) Playing across the Playground: Paradoxes of knowledge creation in the videogame firm. Journal of Organizational Behavior 28(5): 587-605.

Coyle, D (1998) The Weightless Economy. London: Capstone.

DCMS (2001) Creative Industries Mapping Document. London: Department for Culture, Media and Sport.

DCMS (2008) Creative Britain: New talents for the new economy. London: Department for Culture, Media and Sport.

Dymek, M (2010) Industrial Phantasmagoria: Subcultural interactive cinema meets masscultural media of simulation Doctoral Thesis, Royal Institute of Technology, Sweden

Eisenhardt, KM (1989) Building Theories from Case Study Research. Academy of Management Review 14(4): 532-550.

Florida, R (2002) The Rise of the Creative Class. New York: Basic Books.

Gallie, D, Zhou, Y, Felstead, A, and Green, F (2012) Teamwork, Skill Development and Employee Welfare. British Journal of Industrial Relations (forthcoming). 
Grabher, G (2002) Fragile Sector, Robust Practice: project ecologies in new media. Environment and Planning A 34(11): 1911-1926.

Harley, B (2001) Team Membership and the Experience of Work in Britain: An analysis of the WERS98 Data. Work, Employment and Society, 15(4), 721-742.

Hesmondhalgh, D (2010) The Cultural Industries. London: Sage.

Hesmondhalgh, D and Baker, S (2011) Creative Labour: Media Work in Three Cultural Industries. Abingdon: Routledge.

Hodgson, DE (2002) Disciplining the Professional: The case of project management. Journal of Management Studies 39(6): 803-821.

Hodgson, DE (2004) Project Work: The legacy of bureaucratic control in the postbureaucratic organization. Organization 11(1): 81-100.

Hodgson, DE and Cicmil, S (2006) Making Projects Critical. Basingstoke; Palgrave Macmillan. Lampel, J, Lant, T and Shamsie, J (2000) Balancing Act: Learning from organizing practices in cultural industries. Organization Science 11(3): 263-269.

Lawrence, TB and Phillips, N (2002) Understanding cultural industries. Journal of Management Inquiry 11(4): 430-441.

Marks, A and Baldry, C (2009) Stuck in the Middle with Who? The class identity of knowledge workers. Work, Employment and Society, 23(1): 49-65.

Marks, A and Scholarios, D (2007) Revisiting Technical Workers: Professional and organisational identities in the software industry. New Technology, Work and Employment 22(2): 98-117.

Mueller, F, Procter, S and Buchanan, D (2000) Teamworking in its context(s): Antecedents, nature and dimensions. Human Relations 53(11): 1387-1424. 
NESTA (2010) The Money Game: Project finance and video games development in the UK. London: National Endowment for Science, Technology and the Arts.

Nijholt, JJ and Benders, J (2010) Measuring the Prevalence of Self-Managing Teams: Taking account of defining characteristics. Work, Employment and Society, 24(2), 375-385.

Peters, T (1992) Liberation Management. New York: Pan.

PricewaterhouseCoopers (2008) Global Media and Entertainment Outlook 2008-2012. London: PwC.

Roy, M and Audet, M (2003) La transformation vers de nouvelles formes d'organisation plus flexibles: une cadre de référence. Gestion 27(4): 43-49.

Schwaber, K and Beedle, M (2002) Agile Software Development with Scrum. Prentice Hall; New Jersey.

Sennett, R (2009) The Craftsman. London: Penguin.

Silverman, D (2006) Interpreting Qualitative Data: Methods for analyzing talk, text and interaction. London: Sage.

Smith, C and McKinlay, A (2009) Creative Industries and Labour Process Analysis. In: Creative Labour: Working in the Creative Industries. McKinlay, A and Smith, C (eds.) London: Palgrave, 3-28.

Smith, C and McKinlay, A (2009) Creative Labour: Content, Contract and Control. In: Creative Labour: Working in the Creative Industries. McKinlay, A and Smith, C (eds.) London: Palgrave, 29-50.

Thompson, $\mathrm{P}$, Jones, $\mathrm{M}$ and Warhurst, $\mathrm{C}$ (2009) From Conception to Consumption: Creativity and the Managerial Missing Link. In: Creative Labour: Working in the Creative Industries. McKinlay, A and Smith, C (eds.) London: Palgrave, 51-71. 
Townley, B and Beech, N (eds.) (2010) Managing Creativity: Exploring the Paradox. Cambridge: Cambridge University Press.

Townley, B, Beech, N and McKinlay, A (2009) Managing in the Creative Industries: Managing the motley crew. Human Relations 62(7): 939-962.

Tschang, FT (2007) Balancing the Tensions between Rationalization and Creativity in the Video Games Industry. Organization Science 18(6): 989-1005.

Winter, M, Smith, C, Morris, PWG and Cicmil, S (2006) Directions for Future Research in Project Management: The main findings of a UK government-funded research network. International Journal of Project Management 24(8): 638-649.

Damian Hodgson

Manchester Business School, University of Manchester, UK

email : damian.hodgson@mbs.ac.uk

Damian Hodgson is Senior Lecturer in Organisational Analysis at Manchester Business School, University of Manchester. His research focuses on the management and control of expert labour, with a particular focus on project-based organisations.

Louise Briand

Université du Québec en Outaouais (UQO), Canada

email : louise.briand@uqo.ca

Louise Brian is associate professor at the Department of Accounting at the Université du Québec en Outaouais (UQO) in Gatineau, Quebec, Canada and a researcher at the Centre de Recherche sur les Innovations Sociales (CRISES). Her research focuses on issues of control and resistance in knowledgebased organisations. 